\title{
A case study on the international students' social adaptability in Taiwan: A qualitative study
}

Lewis, Amy

University of Hong Kong, Hong Kong, China (alewis@hku.edu)

Ching, Gregory S. $\bowtie$

Lunghwa University of Science and Technology, Taiwan, ROC (gregory_ching@yahoo.com)

$\mathrm{Su}, \mathrm{Yu} \mathrm{Nan}$

National Dong Hwa University, Hualien, Taiwan, ROC (foci@mail.ndhu.edu.tw)

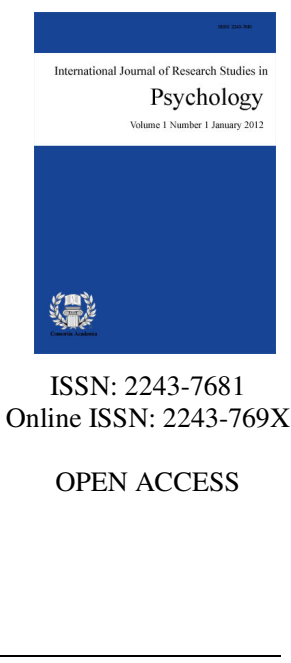

\section{Abstract}

Nowadays, the social network of human beings has been an important issue across different disciplines. However, human beings' social adaptabilities can directly influence how they can establish their social networks. Within the academe, students who go abroad (more commonly known as international students) has the opportunity to learn all kinds of knowledge within various cultures and educational training approaches. Within such concepts of study abroad, socio-cultural issues are deemed important gate-keepers in having a successful international experience. In light of such issues, the current presentation shall showcase the findings of a case study accomplished at a social science university in Taiwan during the 2009 school year. The main purpose of this study is to explore the critical factors that influence the international students' social adaptations. This qualitative study uses both individual and focus group interviews to strengthen the data gathering procedures. A total of 30 international students from 15 countries were invited and interviewed. Data analysis includes constant comparison of gathered facts and generating meaning from the transcribed information. Results show that international students' social adaptabilities (social adaptive skills) can have a direct influence on how they establish their social networks. Some major factors include the availability of cross-cultural opportunities such as foods in night markets, numerous scenic places to visits, and coupled with easy access to mass transportation. The international students' social adaptability is further reinforced by the friendly and receptive nature of Taiwan individuals towards cultural diversity. Lastly, this study also relays some recommendations international students mentioned that will be able to better enhance their study experience.

Keywords: social adaptability; cross-cultural adaptation; international student; qualitative method; internationalization of higher education 


\section{A case study on the international students' social adaptability in Taiwan: A qualitative study}

\section{Introduction}

With the trend of globalization era, studying abroad for students has been a common phenomenon in terms of convenient transportations and advanced information technology. Students who go abroad (the so-called international students) can learn all kinds of knowledge with different cultures and educational training approaches in order to enhance their capabilities (Paige, 1990). In addition, countries around the world have in placed attractive policies to increase their numbers of international students. While there are many international students who are willing to study in a certain country, international students will bring their ideas and thoughts to inspire people of this country which generates a unique value. In essence, international students play an important and particular role in a country.

Realizing that international students are necessary and useful for a country or a school to establish appropriate educational policies, however, the main problem for international student is their ability to adapt in an unfamiliar environment. When international students study in a strange learning environment, they have to learn the communication and problem solving skills through facing difficulties in their life and studying. According to international students' backgrounds, cultures, and training experiences, they could use different approaches to deal with problems based on their existing notions and thinking. For example, the students, traditionally, from America and Europe are more independent and self-reliant than other areas, while getting into troubles. Hence, international students' social adaptability can extremely influence their relations among friends, roommates, and classmates, and many others. Accordingly, the research question of this study can be described as follows:

$>$ What kinds of social relationships do international students have abroad?

$>\quad$ What significant factors would influence international students to formalize their social adaptability?

Comparing with Asian countries, Taiwan has many advantages in political, economic, and learning environments. For building an international academic environment in Taiwan, the government provides many scholarships in order to attract international students to study and learn. Hence, there are thousands of international students who are highly willing to study in Taiwan (Chin \& Ching, 2009; Chou, Roberts, \& Ching, 2010). Consequently, this study uses a social science university as the case of inquiry, which has the most international exchange students and the best programs, as an example to do further research. It could be a suitable research example in analyzing some implications which can offer significant perspective for the vision of internationalization of the universities. Furthermore, this study attempts to employ qualitative approaches to explore the important factors of international students.

This study conducts at total of 7 individual interviews and one focus group interview. The purposes of this study are to 1) analyze international students' social networks and learning experiences overseas, 2) understand the role played by the social network in international students' adaptability, 3) identify the critical factors of international students in their daily and school life, and 4) apply our findings and implications into strategic policies for the government and educational authorities. This study also proposes critical implications for the government as strategic policies to improve the academic environment in present and attract much more foreign students.

\section{Literature review}

International students are defined as individuals who temporarily reside in a country other than their country 
of citizenship in order to participate in international educational exchange as students (Paige, 1990). Social shock is inevitable for International students when trying to fit in a new environment as they may find themselves suddenly living in a different society, culture, and language system. Besides the academic difficulties which all students have to deal with, the international students have to further get used to the new customs, languages, food, living arrangement, social life, and much more. The conditions for stress are abundant, and the possibilities of an unsatisfactory experience are great (Perrucci \& Hu, 1995).

Under the environment of different culture and the geographical distances with their own family and friends, the various follow-up adjustments for international students are necessary without question. Ward and colleagues (1991) have proposed that the cross-cultural adjustments maybe meaningfully divided into two domains: psychological (emotional/affective) and socio-cultural (behavioral). The former refers to psychological well being or satisfaction; while the latter is related to the ability to fit in, to acquire culturally appropriate skill and to negotiate interactive aspects of the host environment (Ward, 1996).

Psychological adjustment, defined in terms of psychological and emotional well-being, is broadly affected by personality, life changes, coping styles and social supports. Psychological adjustments has been associated with personal flexibility, internal locus of control, relationship satisfaction, approach-oriented coping styles and use of humor, while psychological difficulties in sojourners has been linked to a higher incidence of life changes, loneliness, stress, and avoidant coping style (Berno \& Ward, 1998; Ward \& Rana-Deuba, 1999). Socio-cultural adjustment, by contrast, defined in terms of behavioral competence, is more strongly influenced by factors underpinning culture learning and social skill acquisition. These include length of residence in the new culture, cultural knowledge, amount of interaction, and identification with host nationals, cultural distance, language fluency, and acculturation strategies (Searle \& Ward, 1990; Ward \& Kennedy, 1994; Ward \& Searle, 1991). The research referred to socio-cultural adjustment defined above to the term social adaption as how well the international students cope enhance their social adaption.

International students face common as well as their own unique problems. They face the same problems that confront anybody living in a foreign culture, such as racial discrimination, language problems, accommodation difficulties, dietary restrictions, financial stress, misunderstanding, and loneliness (Lin \& Yi, 1997). Students expressing satisfaction with academic performance have succeeded in overcoming the stress associated with new demands of being a student and sojourner. Such students are more likely to complete their programs in a timely manner and to be more effective learner. The inability to deal with stressful circumstances can lead to complaints of nervousness, loneliness, insomnia and physical illness, all of which interfere with their studies (Perrucci \& Hu, 1995).

Although international students find themselves in a new social setting, and the possible undesirable or disruptive experiences may hamper their self-esteem and mastery, the stress-producing conditions are mediated by the social adaption for example, individual resources, supportive social relationships, and coping behavior (Perrucci \& Perrucci, 1990; Pearlin et al., 1981; Turner, 1981). Since the social adaption plays such an important role for international students, the main objective of this research is to investigate what and how international students do to generate their social adaption in Taiwan.

\section{Methodology}

This Qualitative study focused on international students' social adjustment experiences to the campus life and Taiwan. The study combined individual interview and class observation on focus group interview and conducted the triangulation of data analysis then contributed to the research result and recommendation together.

\subsection{The development of interview questions}

Based on the experience interacting with the international students as well as one of research team member's researches, the research team made a draft for interview questions. This first series of interview questions had 
been conducted to the individually pilot study for the first time. Then the research team revised the interview questions with the prior experience of individually pilot interview. Besides effort to rephrase the wording of question to make it more readable and easier to understand, the research team also managed to make the concept of each questions become clearer to avoid misunderstanding. The final version of interview questions thus worked out, and also become the interview questions of focus group interview. These interview questions are as follows:

$>$ Question 1: Tell me about something you like in Taiwan.

$>$ Question 2: In the first month you arrived in Taiwan, how did you settle in? Follow-up Question (FQ): Did someone assist you?

$>$ Question 3: How did you make contacts and friends in Taiwan? FQ: Did you do anything in advance to prepare for this?

$>$ Question 4: Who do you spend most of your time with (studying, hanging out, dating a girlfriend/boyfriend from another country, etc.) and why? FQ: How about during the Chinese holidays and festivals?

$>$ Question 5: Describe an impressive situation when you were interacting with Taiwanese classmates or other Taiwanese students.

$>$ Question 6: What is the difference in your relationship between local (Taiwan) students and when you were a student in your home country? FQ: Did you anticipate this before you came to Taiwan?

Question 7: Describe your support system at the university. FQ: When you encounter a problem, who do you approach?

$>$ Question 8: Could you give a point for Taiwan? If the most satisfied is 10 point and the opposite is given 0 point (for the focus group interview).

\subsection{Participants}

For the individual pilot study and the focus group interview, the research teams selectively enrolled the international students who are really of different nationality rather than Chinese oversea students. Among these participants, three of them are students for Master degree, two of them are for Doctoral degree, two of them are for Bachelor degree, and still with three of them are of Chinese Language Program, which merely aimed to learn Chinese in Taiwan for one year.

\subsection{Research process}

The researchers had conducted two types of interview, one was in the form of individual interview, and another one was conducted in the form of focus group. And, the former one had been planned to be the pilot study of the latter focus group interview.

\subsection{Pilot interview: Individual interview}

The researchers interviewed international student from different countries individually at first. After then, a brief summary was brought to teamwork to discuss the controversial wordings and difficulties may encounter in the future focus group interview. Based on these prior pilot interviews, the researchers then revised and worked out a final form of interview questions of future focus group interview. 


\subsection{Focus group interview}

Before the researchers launched the focus group interview, they recruit participants via posters on campus and female dormitory and international student's email. In total there are 4 interviewees, one moderator, one introducer, and 7 members as research observers attending the focus group interview. The entire interview process was accomplished in English. The entire length of the whole interview took approximately 90 minutes without a break. The moderator hosted and invited the participants to response interview questions according to the order of questions. Interviewees were invited once a person and response questions by turns. At the end of the interview, the moderator turned off the recorder and expressed the appreciation for their attendance and welcome for the further discussion which may not be shared during the interview time. Then the research team has completed the data collection from the individual interview and focus group interview.

\subsection{Data analysis}

After each of the researchers had independently transcribed their individual interview oral content into a written form, the research team then generated a list of key categories and organize the categories into a checklist form for the further analysis of the written transcription as well as the detail information were also required to note below each categories. Weekly two hour sessions were scheduled into presentation and discussion on the key categories as well as the comparison between individual and focus group interview.

\subsection{Reliability and validity of the qualitative research}

Lincoln and Guba (1984) assume that the reliability of qualitative research refers to replication, and the validity refers to the dependability, stability, consistency, predictability, and accuracy. According to the classification of reliability and validity in qualitative research by scholars (Lincoln \& Guba, 1994; LeCompte, Preissle, \& Tesch, 1993), the paper divides reliability and validity into internal reliability, external reliability, internal validity, and external validity, which are respectively illustrated as follows:

\subsubsection{Establishment of internal reliability}

$>\quad$ Objectivity of the inference: subjective reasoning is avoided to the greatest extent, and the verbatim scripts of the interviews and records of the observation are to be directly quoted and the documents are to be analyzed.

$>\quad$ Viewing by the interviews: Before the interviews or observation, the verbatim scripts or records of the observation sorted previously are to be viewed by the objects of interview to correct the errors.

$>$ Use of tools: In addition to the interview notes, a recording pen is to be used to ensure that the data is correct and faultless.

$>$ Subsequent confirmation: as to the information not clear enough or hard to understand or with doubts, reconfirmation by telephone is to be conducted to correct the contents of observation or interviews.

3.7.2 Establishment of external reliability

$>\quad$ The standards for selecting the corrector of the analysis is to be illustrated clearly, and the background and the cause for the selection are also to be explained.

$>\quad$ The background and the role of the researcher and the relationship with the objects of study are to be clearly illustrated.

$>\quad$ The data collected and the analytic methods are to be illustrated in detail and the time and places of the observations and interviews are to be presented clearly. 


\subsubsection{Establishment of internal validity}

$>\quad$ The researcher does not try to intervene in the research context during the course of observations.

$>\quad$ The validity of the study is to be improved through viewing and guidance by peers.

$>$ The study adopts triangulation to correct the data based on the data sources, that is, to collect the data through observations, interviews and data analysis for comparison, and to cross-check the accuracy and reliability of the data.

\subsubsection{Establishment of external validity}

$>\quad$ The backgrounds of the objects of study, such as the teaching experiences, service years, sexes, the present situation, etc, are to be clearly stated.

$>\quad$ The researcher is to reflect and view whether the views are maintained objective and neutral.

\subsection{Research ethics}

As qualitative research focuses on the impact on the study by the relationships between the researcher and the objects of the study, the code of ethics to conduct the research and the moral quality of the researcher are problems that cannot be avoided in qualitative research. Qualitative research is not a soft science, and only requires the researcher to adjust to changing circumstances. Qualitative research also has its solid moral principles and ethical norms, and requires the researcher to consciously comply with these principles and norms. Qualitative researchers believe that good ethics and research methods go hand in hand and complement each other (Sieber, 1992).

Therefore, research ethics are involved at any time in the processes of data collection, such as the interviews, observations and document analysis, or in data analysis and processing. In order to avoid damages to the interests of the objects of study, researchers must be aware of the difference between private domain and public domain of the objects of study, show respect to personal privacy and adhere to the principle of confidentiality. If damage is done to the objects of study, the failure of the study and the distrust of the research by the public will lead to loss that we may not be able to afford. In short, research ethics; as professional ethics, are the professional attitudes and spirits of researchers in the process of the study. The following part explains the three parts of research ethics in the process of the study.

Before entering the study place, the researcher will simply introduce the research steps and research methods, etc., at the first interview to establish the relationship. More importantly, the researcher is to consult the interviewee whether he/she is willing to accept recording and tell the interview about the assurance of anonymity and other relevant issues in advance, prepare the interviewee for some possible sensitive questions, and inform the interviewee that he/she has the right to refuse to quit the study at any time.

After the study place, the researcher will always maintain a relationship of equality and mutual benefit with the object of study. The interviewer and the interviewee exchanges views at any time before and after the interview. As to some opinions and recommendations to amend some of the answers to the questions after the recording, the researcher will authentically make notes and think them over. In the process of the study, the research will fulfill the promise of anonymity and confidentiality, for example, to use an alias to replace the real name of a teacher, to use A Common School to replace the common school of the teacher, etc. And the researcher will prevent the disclosure of the audio files, the verbatim scripts and the documents.

Yu (1998) pointed out that sociologists should describe the phenomenon objectively and faithfully, i.e., reflect the "is/are" reality rather than should be situation. Therefore, based on the premise of adherence to the research ethics, the research report will state and present the facts faithfully. 


\section{Results and discussions}

Documentation and analysis followed Stenhouse's (1985) categorization style of case data. The interviewers summarized key themes, reflections, and insights in a field log after each session. Researchers independently reviewed field logs and focus group recording to generate a list of key themes. Weekly two hour sessions were scheduled to individually present and discuss emerging themes. The aim of the weekly sessions was to identify trends and patterns that reappeared within the individual interviews. A case record was established for each individual interview and focus group interview. Data were kept intact as a way to illuminate meaning and insights in relation to case by case processes and to gleam themes and sub-categories across all cases under study. This approach limited the possibility of losing important themes of each case (Stenhouse, 1985). Primary themes were determined after all data were transcribed as case records. Topics and emerging themes were recorded and a master list was generated. A reexamination of case records was completed followed by formation of one case study.

This study attempts to conduct 7 individual interviews and one focus group interview with international exchange students in Taiwan. As mentioned earlier, this study would like to deeply understand the friend relations of exchange students through these qualitative approaches. The interviewees of this study are from India, The Netherlands, Indonesia, US, Korea, Russia, which enables to increase the reliability and validity of the analysis results. This study tries to come up with 7 questions to ask interviewees and then we conclude several results as follows (as depicted in Tables 1 to 7 ).

\subsection{Question 1: Tell about why you like in Taiwan?}

Table 1 shows the main characteristics for international exchange students who would like to study in Taiwan. The factor of Taiwanese characters is the most importance to attract them to come to Taiwan. For example, interviewees of the focus group emphasized that Taiwanese people are very helpful, polite, patient, friendly, and very welcoming to interact with foreigners. Besides, the factors of food and rich diverse culture are also very critical for them to choose Taiwan. Interviewee $\mathrm{C}$ mentioned that he/she likes to go to night markets for eating in terms of integrated-foods environment. Thus, transportation and modern are the secondary considerations that means the impression of foreigners about the infrastructure of Taiwan becomes better and better. Other factors, such as weather and gender ethnic, are taken into account by international exchange students, because they came from different area and countries that could be appealed to them.

\section{Table 1}

The attractive characteristics for studying in Taiwan

\begin{tabular}{|c|c|c|c|c|c|c|c|}
\hline & Transportation & Weather & Food & Rich diverse culture & Modern & $\begin{array}{l}\text { Taiwanese } \\
\text { characters }\end{array}$ & Gender ethnic \\
\hline $\mathrm{A}$ & V & V & V & & & & \\
\hline B & V & V & & & & V & \\
\hline $\mathrm{C}$ & & & V & & V & V & \\
\hline $\mathrm{D}$ & & V & V & & & V & \\
\hline $\mathrm{E}$ & & & V & V & & V & \\
\hline $\mathrm{F}$ & & & V & V & & V & \\
\hline $\mathrm{G}$ & & & & V & & V & \\
\hline FG & V & V & V & V & V & V & V \\
\hline
\end{tabular}

\subsection{Question 2: How did you settle in for the first month?}

There are three kinds of ways for international exchange students to help them settle in the school, which include asking students from home country, asking Taiwanese students and school services (as shown in Table 2). Interviewee $\mathrm{G}$ stated that the bodies of the school picked him/her up at the airport when he/she arrived. Besides, 
Lewis, A., Ching, G. S., \& Su, Y. N.

he/she would ask students from their home country for several related information of Taiwan. Interviewee D also mentioned that the school provides a picking up service for international exchange student, which is very sweet and helpful for them to be in unfamiliar environments.

Table 2

The helpful ways for settling in the school

\begin{tabular}{lccc}
\hline & Asking students from home country & Asking Taiwanese students & School airport picking up \\
\hline A & V & & \\
B & V & V & \\
C & V & & V \\
D & & & V \\
E & & & V \\
F & V & V & \\
G & V & V & V \\
\hline FG & & & \\
\hline
\end{tabular}

\subsection{Question 3: How did you make contacts and friends in Taiwan?}

In Table 3, the results show that automatic- ethnic related is major factor for international exchange students who make friends with. For instance, Interviewee $\mathrm{F}$ mentioned that the friend relation is formalized naturally. Another is through people from the home country. Interviewee G stated that he/she has many chances to make friends with through his/her home country classmates' Taiwanese bodies at school. The other consideration is knowledge of Chinese.

\section{Table 3}

The major ways to make friends

\begin{tabular}{lccc}
\hline & Automatic ethnic related & Through people from home & Knowledge of Chinese \\
\hline A & V & & \\
B & V & V & V \\
C & V & V & V \\
D & & V & \\
E & V & V & \\
F & V & & V \\
G & V & V & V \\
\hline FG & V & & \\
\hline
\end{tabular}

\subsection{Question 4: Who do you spent most time with and why?}

This question is mainly to realize whom international exchange students get along with, which can briefly portray their friend networks. In Table 4, there are three important persons, including people from the home country, international students, and local students, whom will be concerned about. According to the participants of the focus group, they considered that they could do things with different kinds of persons owing to different purposes. For doing the homework, they would discuss with local student in the same course. For funs, they would like to go outside with students from the home country and other international exchange students. However, some interviewees, such as interviewee $\mathrm{C}$ and interviewee $\mathrm{D}$, sometimes like to stay alone in the dorm or library.

\subsection{Question 5: Describe a typical situation when you were interacting with Taiwanese classmates or other}

Taiwanese students.

When international exchange students interact with local students, they pointed out two situations as shown 
A case study on the international students' social adaptability in Taiwan: A qualitative study

in Table 5. They considered that the leisure time is extremely different from students in their home universities. For Russian and Asian students' viewpoints, Taiwanese students have more time on leisure activities. However, US and European students' viewpoints, Taiwanese students pay more attention to their studies. Consequently, the results show that the different perspectives of interviewees were resulted from their home education system, cultures and backgrounds.

Table 4

People whom they get along with

\begin{tabular}{lcccc}
\hline & People from the home country & International students & Local students & Stay alone \\
\hline A & V & V & V & \\
B & V & V & V & sometimes \\
C & V & V & V & sometimes \\
D & V & V & V & \\
E & & V & V & V \\
F & V & V & V & \\
G & V & V & V & \\
\hline FG & V & V &
\end{tabular}

Table 5

The typical situations

\begin{tabular}{lcc}
\hline & Leisure time & Difference from home country \\
\hline A & & V \\
B & V & V \\
C & & V \\
D & V & V \\
E & & $V$ \\
F & & V \\
G & V & V \\
\hline FG & & \\
\hline
\end{tabular}

4.6 Question 6: What is the difference in your relationship between local students and when you were a student in your home country?

According the responses of interviewees, language is the main difference between local students and students in their home countries. For example, interviewee $\mathrm{G}$ mentioned that Taiwanese students are shy of talking with foreigners in terms of influent English. An interviewee of the focus group said that he/she would like to learn Chinese in order to increase his/her ability of speaking Chinese, because he/she who speaks no good in either Chinese or English is from non-English country. Besides, they found a special situation that Taiwanese students would like to go to do together, so-called collective behaviors. For example, Taiwanese students would go to have a dinner with several classmates, which are not often seen in other countries.

Table 6

The differences between Taiwanese students and home country students

\begin{tabular}{lccc}
\hline & Language & Collective behaviors & Others \\
\hline A & & & \\
B & V & V \\
C & V & V \\
D & V & V \\
E & V & V & \\
F & V & & \\
G & V & V & V \\
\hline FG & V & & \\
\hline
\end{tabular}


4.7 Question 7: Describe your support system at the university.

This question is to reconfirm the friend relationships of international exchange students. When they encountered problems at school, whom would they ask for? In Table 7, the results represent that the friends with the same language, administrative assistants of school, and family are the most important options for them to ask for helps. Accordingly, international exchange students still focused on persons who have the same language, such as their family and home country students, which can decrease the difficulty of conversations during problems solving process. In addition, they also ask for helps from administrative assistants of school, which means the university has a reliable and efficient service to deal with their problems. According to Table 7, the girlfriend, or searching by themselves are concluded in a minor ways.

\section{Table 7}

The support system of international exchange students

\begin{tabular}{lcccccc}
\hline & Self & Family & Girlfriend & Friends & School & Contact with home country \\
\hline A & & V & V & & V & V \\
B & & V & V & V & V & V \\
C & V & V & & V & V & \\
D & & V & V & & \\
E & & V & & V & V & V \\
F & & & & V & V & V \\
G & & FG & V & V & V & V
\end{tabular}

\section{Implications}

According to the findings, international students can easily make friends with not only Taiwanese students but also other international exchange students at the same school. It is obvious that international students are willing to know other students at the same school, although they may get along with different kinds of students in terms of different purposes (as shown in Table 4). In other words, international students always have high intentions and courage to explore their friend relationships.

Consequently, when international students stay in a new learning environments (such as a university), they will naturally and automatically search proper persons to work and study together according to their basic needs (e.g. life problems solving or homework studying). They can formalize a social network for themselves by implementing their adaptabilities in order to immediately support members of the network. Furthermore, some international students could belong to different social networks, called key persons, so they can explore diverse friends and ask for supports by key persons linking other social networks. Accordingly, the better the social adaptability international students have, the stronger the social network will be.

When the country have different kinds of people with diverse cultures, backgrounds, or races (e.g. US), that will increase its competency and diversity to enhance its total abilities. Hence, universities should apply this concept to their educational policies. A university needs to plan appropriate programs to attract international students to join its learning environment. As mentioned earlier, international students pay attention to the existing school services (e.g. picking up service or scholarships) for the considerations of school selection. Besides, according to the findings, the culture factor is an important characteristic to influence international students' school selection. Furthermore, school administrators need to design the promotion strategies of its specific culture to attract more international students. The culture-based courses can be delivered to international students for further learning and studying.

The language factor is also another important consideration for international students to build their social networks. Although international students can make contacts with local students and other ones, they still are willing to get along with international students because of the communication and representation skills of local 
students in English. Managers of school should have attractive policies to encourage local students to increase their abilities of communication and representation skills, especially for meeting with international students. It will increase local students' global perspectives, improve their communication skills within English, and learn from international students' experiences.

\section{Conclusions}

In this research, both of the individual and focus group interview are applied to investigate international students' social network and their social adaptability as well as their life experiences in Taiwan. Through the identification on critical factors and further analysis of the interview data, the research had demonstrated the following results: (1) the satisfied factors for studying in Taiwan are most strongly connected with the food, personal character of Taiwan, and also the convenient transportation, delicious food and cultural diversity of Taiwan; (2) for the majority of international students in this research, the students are their home country and school service had been indicated as the first major approach to settle up for the first arriving month. And, merely two seventh of these students to ask or receive the help from Taiwanese students during their first arrival period; (3) almost all of the international students in this research shown to automatically start their contact and friendship, especially start with their ethnicity. Besides, the half of them started their contacts and friendship through the social network of people from their home country and people with the same language as well as the half of them related their contact with their knowledge of Chinese; (4) the statistics in this research also manifestly shown these international students spent their time functionally with local students for study and with international students for entertainment and leisure time; (5) for the most impressive images while interacting with Taiwanese students was attributed to the different cultural background and the different educational pedagogy from those in the international students' home country; and (6) the language gap had been reinforced again in this research that influenced the relationship between the Taiwanese and international students. The Collective behaviors also accounts for the influence effect of the half international students in this research.

However, there are four limitations of this study as follows. First, finding numerous international students who are suitable for the research target is very important. In this research, the more participants have joined in our research, the more data we can gain. But, in fact, it's hard to invite a lot of international students to join the focus group interview. Hence, with fewer participants, it might make the result different. The second limitation is the uncertainty of the research object. Because the participants in the focus group were needed to express themselves, and the different personality will change the way they communicated with people. Therefore, it might increase the uncertainly of this study. Third, the qualitative research should increase more subjective opinions. Facing the same interview question, different interviewees might have different point of views. Consequently, that will affect the research results. Even the outlier will make the consequence more meaningful, but with too much subjective opinions, the consequence might not be so reliable. Last, the research results will be affected by different factors. The way how people think and act is extremely complicated, so it's hard to find out the reasons. When the researchers try to discover the connection between people and environments, they can't fully take all considerations of human beings into account.

Consequently, this research further provided a significant overview picture of international students' assist system in at the university. The half of the international students conclusively expressed their assists have been mostly from their family, friends with the same language and school administrative service. The important role of schools and local students' social network with international students therefore has been increasingly rising in the present and future. In this study, researchers understand international students' social network and their social adaptability as well as their life experiences in Taiwan. Because of limited time financial strength and manpower, so the research needs to make up a deficiency. Consequently, researchers can focus on the following topics in the future: (1) to employ quantitative approaches to evaluate our findings. Through different approaches, the research findings may confirm and possess value; (2) to conduct interviews by adding the Taiwanese interviewees to enhance the reliability and validity. Researchers collect data from international students but did not know what the vibration of Taiwanese students in the university; and (3) to utilize other cases as evidences to 
support our findings. The government provides many scholarship and subsidy for international students on different campus in Taiwan, and then research findings from other cases may advocate our results. Eventually, the topic about international students may attract more and more researchers and accomplish important findings and results.

\section{References:}

Berno, T., \& Ward, C. (1998). Psychological and socio-cultural adjustment of international students in New Zealand. Paper presented at the Annual Conference of the Society of Australasian Social Psychologists, Christchurch, New Zealand.

Chin, M. C., \& Ching, G. S. (2009). Trends and indicators of Taiwan's higher education internationalization. The Asia-Pacific Education Researcher, 18(2), 185-203. <http://dx.doi.org/10.3860/taper.v18i2.1322>

Chou, C. P., Roberts, A., \& Ching, G. S. (2012). A study on the international students' perception and norms in Taiwan. International Journal of Research Studies in Education, 1(2), 71-84. <http://dx.doi.org/10.5861/ijrse.2012.v1i2.76>

Guba, E. G., \& Lincoln, Y. S. (1994). Competing paradigms in qualitative research. In N. K. Denzin \& Y. S. Lincoln, Handbook of qualitative research (pp. 105-117). Thousand Oaks, CA: Sage Publications.

LeCompte, M. D., Preissle, J., \& Teach, R. (1993). Ethnography and qualitative design in education research (2nd ed.). New York: Academic Press.

Lin, J. C., \& Yi, J. K. (1997). Asian international students' adjustment: issues and program suggestion. College Student Journal, 31(4), 473-485.

Paige, M. R. (1990). International students: Cross-cultural psychological perspectives. In R. W. Brislin (Ed.), Applied cross-cultural psychology (pp.161-185). Newbury Park, CA: Sage.

Pearlin, L. I., Lieberman, M. A., Menaghan, E. G., \& Mullan, J. T. (1981). The stress process. Journal of Health and Social Behavior, 22, 337-356. <http://dx.doi.org/10.2307/2136676>

Perrucci, R., \& Hu, H. (1995). Satisfaction with social and educational experiences among international graduate students. Research in Higher Education, 36(4), 491-508. <http://dx.doi.org/10.1007/BF02207908>

Perrucci, R., \& Perrucci, C. C. (1990). Unemployment and mental health: Research and policy implications. In J. R. Greenley (Ed.), Research in community and mental health: Mental disorder in social context (pp.237-264). Greenwich, CT: JAI Press.

Searle, W., \& Ward, C. (1990). The prediction of psychological and socio-cultural adjustment during cross-cultural transitions. International Journal of Intercultural Relations, 14, 449-464. <http://dx.doi.org/10.1016/0147-1767(90)90030-Z>

Stenhouse, L. (1985). Action research and the teacher's responsibility. In Rudduck, J. \& Hopkins, D. (Eds.), Research as a basis for teaching: Readings from the work of Lawrence Stenhouse (pp. 56-59). London: Heinemann Educational.

Turner, R. J. (1981). Social support as a contingency in psychological well-being. Journal of Health and Social Behavior, 22, 357-367. <http://dx.doi.org/10.2307/2136677>

Ward, C. (1996). Acculturation. In D. Landis \& R. Bhagat (Eds.), Handbook of intercultural training (2nd. ed., pp.124-147). Thousand Oaks, CA: Sage.

Ward, C., \& Kennedy, A. (1994). Acculturation strategies, psychological adjustment and socio-cultural competence during cross-cultural transitions. International Journal of Intercultural Relations, 18, 329-343. <http://dx.doi.org/10.1016/0147-1767(94)90036-1>

Ward, C., \& Rana-Deuba, A. (1999). Acculturation and adaptation revisited. Journal of Cross-Cultural Psychological, 30, 372-392. <http://dx.doi.org/10.1177/0022022199030004003>

Ward, C., \& Searle, W. (1991). The impact of value discrepancies and cultural identity on psychological and sociocultural adjustment of sojourners. International Journal of Intercultural Relations, 15, 209-225. <http://dx.doi.org/10.1016/0147-1767(91)90030-K>

Yu, H. Y. (1998). Social research ethics [In Chinese]. Taipei: San-min Bookstore. 